\title{
Incidence and risk factors for disease and non-battle injury aboard the hospital ship USNS COMFORT during a Humanitarian Assistance and Disaster Response Mission, Continuing Promise 2011
}

Andy Chern ${ }^{1}$, Andrea McCoy ${ }^{2}$, Tracy Brannock ${ }^{3}$, Gregory J. Martin ${ }^{4}$, William T. Scouten ${ }^{5}$, Chad K. Porter ${ }^{2}$ and Mark S. Riddle ${ }^{2^{*}}$

\begin{abstract}
Background: Disease and non-battle injury (DNBI) are a leading cause of morbidity in deployments and can compromise operational mission performance. No study to date has examined DNBI incidence and impact aboard humanitarian aid/disaster response (HADR) mission ships.

Methods: From April to September 2011, US military and civilian personnel participated in Continuing Promise 2011, a HADR training mission aboard USNS COMFORT (T-AH 20). Health surveillance was conducted for the purpose of assessing DNBI trends and improving force health protection during the deployment through passive surveillance, collection of DNBI data among those seeking care at the ship's clinic, and actively through use of an anonymous weekly, self-report questionnaire. Categorical and total DNBI incidence rates were calculated per 100 person-weeks and incidence rate ratios (IRR) were calculated utilizing a negative binomial model to assess potential risk factors.
\end{abstract}

Results: The leading syndrome-specific cause of weekly visits to the ship's clinic was gastrointestinal (Gl) followed by dermatologic and respiratory conditions (2.22, 1.97, and 1.46 cases per 100 person-weeks, respectively). The top three categorical DNBI were similarly represented by the questionnaire, with respiratory conditions having the highest reported rate followed by dermatologic and GI (11.79, 8.71, and 7.38 cases per 100 person-weeks, respectively). Gl had the highest morbidity measures accounting for $61.9 \%$ of lost work days and $27.3 \%$ of reported moderate/severe impact to mission performance. Several factors were also associated with increased DNBI rates including personnel ages 26-36 (IRR $=1.23$ ), officers (IRR $=1.23)$, days-off-ship (IRR $=1.09)$, and affiliation with nursing services (IRR $=1.48)$, naval mobile construction battalion ( $I R R=3.17)$, and security $(\operatorname{IRR}=1.71)$.

Conclusions: DNBI can significantly impact mission performance on HADR missions, and establishing baseline rates and identifying risk factors can help improve force health protection in future HADR missions.

Keywords: Epidemiology, Humanitarian assistance, Disaster response, Occupational medicine, Military, Disease and non-battle injury, DNBI

\footnotetext{
* Correspondence: mark.s.riddle10.mil@mail.mil

${ }^{2}$ Enteric Diseases Department, Naval Medical Research Center, 503 Robert

Grant Avenue, Silver Springs, MD 20910, USA

Full list of author information is available at the end of the article
} 


\section{Background}

Disease and non-battle injuries (DNBI) can significantly impact operational missions and compromise readiness through loss of productivity and work days. Historically, DNBI have greatly outnumbered combat related injuries and led to considerable reduction in effectiveness. In World War II, the Korean War, and Vietnam conflict, DNBI accounted for over $60 \%$ of non-effective rates, and even more recently during the initial phases of Operation Iraqi Freedom (OIF), $75 \%$ of all hospitalizations were due to DNBI $[1,2]$. Although DNBI can compromise readiness during combat deployments, DNBI also effect peacetime deployments. A few studies have even indicated higher DNBI rates during non-combat operations [3, 4].

Since 1997, the Department of Defense (DoD) has recognized the impact of DNBI on force health protection and mandated surveillance and reporting for DNBI among deployed units [5]. However, among these deployed units, not all DNBI are distributed similarly across different operational environments. A study of over 4000 deployed US Army soldiers during OIF showed that musculoskeletal injuries (e.g., sports/athletics and heavy gear/ lifting) and psychiatric conditions encompassed nearly $75 \%$ of the recorded DNBI [6]. Whereas, a study of the US Fifth Fleet found other medical/surgical conditions, dermatologic, and respiratory disease as the top three DNBI categories [7]. And, even aboard ships, several studies have found differential DNBI rates among different ship sizes $[3,4,7]$.

The mandated surveillance and reporting by the DoD, however, only captures individuals actively seeking medical care in the clinic. Consequently, DNBI rates reported from clinic data underreport the true incidence of the diseases and injuries. Moreover, the percentage of those with DNBI seeking medical care varies across different DNBI categories. In studies among military personnel deployed to Iraq and Afghanistan, of those reporting infectious gastroenteritis, acute respiratory illness, and non-battle injury, only 22, 50 and $85 \%$ (respectively) reported seeking medical care $[8,9]$.

Although previous studies have reported DNBI rates on US Navy ships during both combat and peacetime deployments, no study to date has examined DNBI rates aboard hospital ships engaged in humanitarian aid/disaster response (HADR) missions. Given the nature of HADR training and the operational mission of a hospital ship, the ship's composition, consisting mostly of medical personnel, and their exposures are likely different than other Navy ships. Medical personnel, in particular, have a history of underreporting injuries and illnesses and have easier access to self-treatment [10-12].

Accounting for the unique population aboard HADR mission ships, the primary objectives of this study were to describe and compare total and categorical DNBI incidence rates from the ship's clinic (passive) and survey questionnaire (active) surveillance data aboard a HADR mission ship, USNS COMFORT, during the Continuing Promise 2011 (CP 11) mission. Additionally, we aimed to determine potential risk factors among those that had a DNBI and sought medical care as well as describe morbidity measurements associated with categorical DNBI.

\section{Methods}

The population in this study included all individuals serving aboard the USNS COMFORT during its 5-month $\mathrm{CP}$ 11 mission including uniformed service members (US and foreign) and non-governmental organization personnel. Weekly de-identified clinical aggregate data were compiled as mandated by the DoD for force health protection and public health surveillance for total and categorical DNBI including time aboard ship [5]. The case definitions for categorical clinic DNBI were defined in accordance with the DoD procedures for deployment health surveillance; specific case definitions are listed elsewhere [13-15]. Additionally, "combat/operational stress reactions" and "psychiatric, mental disorders" as defined by the DoD for deployment health surveillance were consolidated collectively under mental health conditions for analyses in this study. And, incidence rates for total and categorical DNBI, light duty, lost days, and admissions were calculated per 100 person-weeks. To further depict the burden of disease and injury, a graphical display was constructed plotting categorical DNBI incidence rates against categorical lost duty days per 100 categorical DNBI events.

An additional cross-sectional DNBI anonymous questionnaire utilizing a convenience sampling design was administered weekly to approximately $15 \%(n \approx 150)$ of the ship population to identify potentially uncaptured DNBI in the preceding week given that traditional DNBI data relies upon actively seeking healthcare. Questionnaires were administered to the available personnel reporting during morning muster or while awaiting transport to shore weekly. Each questionnaire identified basic demographics, departmental unit, days off the ship within the past week, seeking medical care within the past week (i.e. going to the clinic), 'yes or no' questions concerning categorical DNBI, and a question on DNBI impact on mission performance. Midway through the CP 11 mission, the questionnaire expanded the DNBI impact element beyond a dichotomous variable to produce additional granularity on impact to mission performance to better assist in force health protection.

Descriptive analyses were performed on demographic variables. Incidence rates for total and categorical DNBI from the survey were similarly calculated per 100 person-weeks. Negative binomial regression models were 
utilized to estimate unadjusted and adjusted relative incidence rate ratios (IRR) and to assess potential predictors of DNBI. Only statistically significant variables from univariate models were included in multivariate analyses $(p<0.05)$. Moreover, continuous variables (i.e., age and days-off-ship) and association with risk were tested for linearity and re-categorized if non-linear. Impact analyses utilized data after the questionnaire update previously described. Data from personnel indicating moderate and severe degree of impact were analyzed together to increase statistical power. Missing data on impact severity was excluded from analyses. Negative binomial modeling was also utilized to calculate IRR for those with DNBI seeking medical care. A negative binomial regression model was chosen due to the nature of the count data and to account for potential overdispersion.

All analyses were performed with IBM SPSS Statistics 22 (IBM Corp. Released 2013. IBM SPSS Statistics for Windows, Version 22.0. Armonk, NY: IBM Corp), and applicable analyses operated under a two-tailed significance level set at $p$-values of less than 0.05 .

\section{Results}

During the 5-month CP 11 mission, approximately 900 personnel were serving aboard USNS COMFORT each week. Table 1 shows the demographic characteristics of personnel from clinic and the questionnaire. The weekly average number of men and women serving aboard the ship was $652(72.2 \%)$ and $251(27.8 \%)$, respectively. Among those administered the questionnaire, the median age was 29 (interquartile range $[I Q R]=24-36$ years) and there was slight oversampling of women (32.7\%) compared to the weekly average number of women aboard the ship (27.8\%). Personnel sampled from the questionnaire were predominantly affiliated with the Navy $(79.3 \%)$ followed by non-governmental organizations (6.8\%), which was similar to the average weekly distribution on the ship. Forty percent of the personnel completing the questionnaire reported their affiliation with a medically-related service (i.e. medical services, surgical services, and nursing services). Among those surveyed, there was no significant difference in demographic characteristics between those reporting a DNBI and those reporting no DNBI (data not shown). A total of 17,176 person-weeks (4779 female personweeks) were represented from the clinic data, and a total of 3156 person-weeks (1031 female person-weeks) were represented from the questionnaire data.

Table 2 provides the categorical DNBI rates from both the ship's clinic and the questionnaire surveillance data. The total weekly DNBI rate from clinic was 10.5 cases per 100 person-weeks. The DNBI categories of other medical/surgical, gastrointestinal infection, dermatologic and respiratory conditions were among the highest (3.18, 2.22, 1.97 and 1.46 cases per 100 person-weeks, respectively). In contrast, the questionnaire identified almost a 4 fold increase in the total DNBI rate compared to the clinic (42.2 versus 10.5 cases per 100 person-weeks). Respiratory, dermatologic, gastrointestinal infection and mental health conditions were among the highest identified in the questionnaire (11.79, 8.71, 7.38, and 5.29 cases per 100 person-weeks). Interestingly, the questionnaire identified a much lower rate for medical/surgical conditions compared to the clinic ( 0.76 versus 3.18 cases per 100 person-weeks, respectively), but at the same time, the questionnaire did uncover a greater than a 10 fold increase rate in mental health conditions compared to the clinic (5.29 versus 0.51 cases per 100 person-weeks, respectively).

During the mission, the ship's clinic captured light duty days, lost days, and admissions at a rate of 2.23, 1.89 , and 0.07 per 100 person-weeks, respectively (data not shown in table). The majority of light duty days were attributed to other medical/surgical conditions (140/383, $36.6 \%$ ), which was also the leading cause for clinic visits (546/1809, $30.2 \%)$. Gastrointestinal infections were the primary DNBI leading to lost work days (201/325, $61.8 \%)$ and were the second leading cause for clinic visits (381/1809, $21.1 \%)$. The relationship between lost work days and DNBI incidence is depicted in Fig. 1, which shows a significant burden from gastrointestinal infections. Personnel answering the questionnaire also corroborated this result indicating that gastrointestinal infections were also the primary DNBI that had the most adverse impact on their mission performance (Table 2). Gastrointestinal conditions accounted for $21.6(32 / 148)$ and $27.3(21 / 77)$ percent of those reporting minor and moderate/severe impacts, respectively. Respiratory conditions followed gastrointestinal infections as the second leading DNBI causing moderate/severe degree of impact to mission performance, accounting for $12 \%(39 / 325)$ of all lost work days.

Table 3 displays the number of personnel reporting and seeking care for DNBI as well as the differential DNBI counts based on the questionnaire. Overall, the questionnaire identified $29.2 \%(921 / 3156)$ of respondents that self-reported at least one DNBI. However, only $16.3 \%$ (150/921) reporting a DNBI sought medical care from the ship's clinic. Respiratory and gastrointestinal conditions were the most common DNBI associated with seeking medical care $(44 \%, 113 / 257)$. However, personnel reporting a medical/surgical condition or fever had the highest proportion within a DNBI category to seek medical care (54.2 and $45.8 \%$, respectively).

Table 4 displays the results of the univariate and multivariate analyses. Of note, age was initially divided into 6 categories, but due to a lack of linearity was re-categorized 
Table 1 Demographics of personnel surveyed and serving aboard USNS COMFORT on CP11

\begin{tabular}{|c|c|c|}
\hline & $\begin{array}{l}\text { Ship population } \\
\text { (weekly average) }\end{array}$ & $\begin{array}{l}\text { Enhanced DNBI } \\
\text { questionnaire }\end{array}$ \\
\hline \multicolumn{3}{|l|}{ Gender } \\
\hline Male & $652(72.2)$ & $2038(64.6)$ \\
\hline Female & $251(27.8)$ & $1031(32.7)$ \\
\hline Missing & N/A & $87(2.8)$ \\
\hline \multicolumn{3}{|l|}{ Age } \\
\hline Median [IQR] & & 29 [24-36] \\
\hline$\leq 25$ & & $976(30.9)$ \\
\hline $26-35$ & & $1294(41.0)$ \\
\hline $36-45$ & & $496(15.7)$ \\
\hline $46-55$ & & $142(4.5)$ \\
\hline$\geq 56$ & & $128(4.1)$ \\
\hline Missing & & $120(3.8)$ \\
\hline \multicolumn{3}{|l|}{ Service branch } \\
\hline Army & $11(1.2)$ & $71(2.3)$ \\
\hline Air Force & $42(4.7)$ & $196(6.2)$ \\
\hline Navy & $689(76.6)$ & $2503(79.3)$ \\
\hline NGO & $54(6.0)$ & $213(6.8)$ \\
\hline Other & $104(11.6)$ & $116(3.7)$ \\
\hline Missing & N/A & $57(1.8)$ \\
\hline \multicolumn{3}{|l|}{ Rank } \\
\hline Enlisted & $569(63.3)$ & $1946(61.7)$ \\
\hline Officer & $203(22.5)$ & $671(21.3)$ \\
\hline Civilian & $127(14.1)$ & $269(8.5)$ \\
\hline Missing & N/A & $270(8.6)$ \\
\hline \multicolumn{3}{|l|}{ Department } \\
\hline Air detachment & & $128(4.1)$ \\
\hline Boat detachment & & $34(1.1)$ \\
\hline $\begin{array}{l}\text { Department of Ancillary } \\
\text { Services }^{\mathrm{a}}\end{array}$ & & $195(6.2)$ \\
\hline Destroyer Squadron & & $50(1.6)$ \\
\hline $\begin{array}{l}\text { Department for } \\
\text { Administration }\end{array}$ & & $291(9.2)$ \\
\hline Medical services & & $493(15.6)$ \\
\hline Surgical services & & $411(13.0)$ \\
\hline Nursing services & & $374(11.9)$ \\
\hline $\begin{array}{l}\text { Maritime Expeditionary } \\
\text { Security Squadron }\end{array}$ & & $93(2.9)$ \\
\hline $\begin{array}{l}\text { Naval Mobile } \\
\text { Construction Battalion }\end{array}$ & & $65(2.1)$ \\
\hline Manpower/Personnel & & $60(1.9)$ \\
\hline Security & & $315(10.0)$ \\
\hline Information operations & & $67(2.1)$ \\
\hline Communications & & $53(1.7)$ \\
\hline Public Affairs Office/Band & & $74(2.3)$ \\
\hline
\end{tabular}

Table 1 Demographics of personnel surveyed and serving aboard USNS COMFORT on CP11 (Continued)

\begin{tabular}{ll}
\hline Translator & $71(2.2)$ \\
Operations & $66(2.1)$ \\
Other & $316(10.0)$ \\
\hline
\end{tabular}

${ }^{\mathrm{a}}$ Department of Ancillary Services includes radiology, pharmacy,

and laboratory

Data not obtained for age and department for ship population

into 3 age groups. Days-off-ship was kept as a continuous variable based on graphical and quadratic analyses.

In univariate analyses, we found an increased rate of DNBI in personnel ages 26-35 (IRR $=1.17, p=0.049)$ compared to the youngest age category, and civilians had a lower rate of DNBI (IRR $=0.76, p=0.024)$ compared to enlisted. We also observed a $10 \%$ increase in DNBI rate for each additional day reported off the ship (IRR $=1.10, p<0.001)$. Additionally, mission locations to Jamaica, Peru and Haiti had lower DNBI rates (IRR = $0.75,0.70$ and 0.52 , respectively), whereas, missions to Ecuador, Colombia and El Salvador had higher rates $(\operatorname{IRR}=1.60,1.39$ and 1.60, respectively) relative to all other mission locations. Personnel in the surgical services had a lower rate of DNBI, while those in nursing, naval mobile construction battalion, and security all had higher DNBI rates compared to all other departmental units. The only variable associated with seeking medical care was the degree of impact on mission performance in an apparent dose-response relationship. Respondents reporting minor and moderate/severe impacts were 3.67 and 5.90 times more likely to seek medical care compared to those reporting no impact to mission performance from their DNBI (data not shown).

After controlling for important covariates, personnel between the ages of 26-35 and days spent off the ship retained significance. Officers had a 1.23 times greater risk of DNBI compared to the enlisted ranks $(p=0.009)$. Mission locations in Ecuador, Colombia, Nicaragua, Guatemala and El Salvador had increased IRR ranging from 1.39 to 2.06. The low IRR for personnel in the surgical services no longer was significant. Nursing, naval mobile construction battalion and security, however, continued to have greater IRR compared to all other services $(\operatorname{IRR}=1.48,3.17$ and 1.71 , respectively).

\section{Discussion}

This study provides the first baseline assessment of the incidence and impact of DNBI specifically aboard a US Navy hospital ship participating in a HADR training mission. Consistent with prior DNBI studies, our data shows that DNBI are underreported $[8,9,16]$. The overall clinic DNBI rate was 10.05 cases per 100 personweeks, but our questionnaire identified a greater than 4 fold increase in the DNBI rate at 42.17 cases per 100 
Table 2 DNBI rates and impact measures from aggregate clinic visits and questionnaire during CP11

\begin{tabular}{|c|c|c|c|c|c|c|c|c|c|c|}
\hline & \multicolumn{2}{|c|}{ Clinic visits } & \multicolumn{3}{|l|}{ Clinic visits } & \multicolumn{2}{|c|}{$\begin{array}{l}\text { Enhanced DNBI } \\
\text { questionnaire }\end{array}$} & \multicolumn{3}{|c|}{ Enhanced DNBI questionnaire ${ }^{b c}$} \\
\hline & $\overline{R a t e}$ & $95 \% \mathrm{Cl}$ & $\begin{array}{l}\text { Light duty } \\
\text { days (\%) }\end{array}$ & $\begin{array}{l}\text { Lost work } \\
\text { days (\%) }\end{array}$ & Admissions (\%) & $\overline{R a t e}$ & $95 \% \mathrm{Cl}$ & No impact (\%) & $\begin{array}{l}\text { Minor } \\
\text { impact (\%) }\end{array}$ & $\begin{array}{l}\text { Moderate/severe } \\
\text { impact (\%) }\end{array}$ \\
\hline Respiratory & 1.46 & $1.29,1.65$ & $13(3.4)$ & $39(12.0)$ & $1(8.3)$ & 11.79 & $10.63,13.03$ & $62(26.7)$ & $20(13.5)$ & $13(16.9)$ \\
\hline Dermatologic & 1.97 & $1.77,2.19$ & $72(18.8)$ & $5(1.5)$ & $1(8.3)$ & 8.71 & $7.73,9.79$ & 69 (29.7) & 32 (21.6) & $4(5.2)$ \\
\hline Gastrointestinal & 2.22 & $2.00,2.45$ & $13(3.4)$ & $201(61.8)$ & $3(25.0)$ & 7.38 & $6.48,8.38$ & $37(15.9)$ & $32(21.6)$ & $21(27.3)$ \\
\hline Gynecologic $^{a}$ & 0.86 & $0.62,1.15$ & $0(0.0)$ & $2(0.6)$ & $0(0.0)$ & 0.87 & $0.43,1.60$ & $3(1.3)$ & $1(0.7)$ & $0(0.0)$ \\
\hline Heat injury & 0.03 & $0.01,0.07$ & $0(0.0)$ & $1(0.3)$ & $0(0.0)$ & 1.87 & $1.44,2.40$ & $9(3.9)$ & $13(8.8)$ & $6(7.8)$ \\
\hline $\begin{array}{l}\text { Sports/Recreation } \\
\text { injury }\end{array}$ & 0.13 & $0.08,0.19$ & $40(10.4)$ & $2(0.6)$ & $0(0.0)$ & 1.49 & $1.11,1.96$ & $12(5.2)$ & $5(3.4)$ & $2(2.6)$ \\
\hline MVA & 0.00 & $0.00,0.00$ & $0(0.0)$ & $0(0.0)$ & $0(0.0)$ & 0.03 & $0.00,0.16$ & $0(0.0)$ & $0(0.0)$ & $0(0.0)$ \\
\hline $\begin{array}{l}\text { Work/Training } \\
\text { Injury }\end{array}$ & 0.34 & $0.26,0.44$ & $58(15.1)$ & $12(3.7)$ & $0(0.0)$ & 0.98 & $0.68,1.38$ & $1(0.4)$ & $3(2.0)$ & $1(1.3)$ \\
\hline Other injury & 0.17 & $0.12,0.24$ & $47(12.3)$ & $3(0.9)$ & $0(0.0)$ & 0.86 & $0.58,1.23$ & $6(2.6)$ & $5(3.4)$ & $2(2.6)$ \\
\hline Ophthalmologic & 0.13 & $0.09,0.20$ & $0(0.0)$ & $3(0.9)$ & $0(0.0)$ & 1.08 & $0.76,1.49$ & $3(1.3)$ & $3(2.0)$ & $4(5.2)$ \\
\hline STI & 0.03 & $0.01,0.07$ & $0(0.0)$ & $0(0.0)$ & $0(0.0)$ & 0.03 & $0.00,0.16$ & $0(0.0)$ & $0(0.0)$ & $0(0.0)$ \\
\hline Mental health & 0.51 & $0.41,0.62$ & $0(0.0)$ & $1(0.3)$ & $2(16.7)$ & 5.29 & $4.53,6.14$ & $22(9.5)$ & $28(18.9)$ & $11(14.3)$ \\
\hline Fever & 0.02 & $0.00,0.05$ & $0(0.0)$ & $0(0.0)$ & $0(0.0)$ & 1.52 & $1.13,2.00$ & $5(2.2)$ & $4(2.7)$ & $9(11.7)$ \\
\hline Other Med/Surgical & 3.18 & $2.92,3.45$ & $140(36.6)$ & $49(15.1)$ & $4(33.3)$ & 0.76 & $0.50,1.11$ & $3(1.3)$ & $2(1.4)$ & $4(5.2)$ \\
\hline Dental & & & & & & 0.10 & $0.02,0.26$ & $0(0.0)$ & $0(0.0)$ & $0(0.0)$ \\
\hline Neurologic & 0.10 & $0.06,0.16$ & $0(0.0)$ & $3(0.9)$ & $1(8.3)$ & & & & & \\
\hline Total & 10.53 & $10.05,11.03$ & $383(100.0)$ & $325(100.0)$ & $12(100.0)$ & 42.17 & $39.95,44.48$ & $232(42.1)$ & $148(26.9)$ & $77(14.0)$ \\
\hline
\end{tabular}

Data not obtained for clinic dental or questionnaire neurologic

Rates are in cases per 100 person-weeks

${ }^{a}$ Gynecologic rates calculated using female person-time

${ }^{\mathrm{b}}$ Impact analysis accounting for periods after implementing updated questionnaire at week 13

${ }^{c} 17 \%$ with a DNBI did not indicate any degree of impact

$\mathrm{Cl}$ confidence interval, MVA motor vehicle accident, STI sexually transmitted infection

person-weeks. The overall clinic-based DNBI rate was also $\geq 2$ times higher than the rates observed in two nonhumanitarian shipboard studies (DNBI rates between 4.1 and 4.4 cases per 100 person-weeks) [7, 17]. In contrast, the rate of admissions during the CP 11 mission ( 0.07 admission per 100 person-weeks) was similar to the rate of a non-humanitarian U.S. Fleet during peacetime deployment (0.06 admission per 100 person-weeks) [17].

Our study also showed a relatively low proportion of personnel seeking medical care compared to previous DNBI studies. In two separate studies of service members deployed to Iraq and Afghanistan, the percentage of those reporting non-battle injuries (i.e., sports/athletics, heavy gear/lifting, fall, machinery/tools, vehicle accident, other) that sought medical care ranged from 77 to nearly $85 \%$ compared to no greater than $29 \%$ for any injury category in our study $[9,16]$. Even among the specific gastrointestinal and respiratory diseases, the rates we observed were on the lower end of those seen in other studies. The rates for seeking medical care from our study were 23.2 and $15.9 \%$, respectively, where other studies of personnel deployed to southwest Asia and the
Middle East ranged from 22.4 to 48.3 \% for diarrheal diseases and 17 to $50 \%$ for respiratory diseases $[8,16]$. These lower rates for gastrointestinal infection were even more surprising as there were frequent health threat briefs and active messaging for people to seek care for diarrhea and/or vomiting (Riddle, personal communication). While it is unclear why we observed lower rates of seeking medical care among those with a DNBI, one explanation could be the different composition of personnel aboard the ship. Given the relatively large proportion of medical providers on the ship, informal medical care may have been common. In a survey study by Gendel and colleagues, $97 \%$ of physicians surveyed reported providing informal care (e.g., prescribing without an official clinic visit) for minor conditions, and as many as $59 \%$ of physicians reported providing informal care even to the degree of treating chronic or serious medical conditions [13]. However, we did not observe a lower rate of seeking medical care among any of the medical services potentially indicative of receiving informal medical care from medical colleagues. Nonetheless, increased study of the potential for informal care 


\section{Association of Categorical DNBI Incidence and Lost Duty Days}

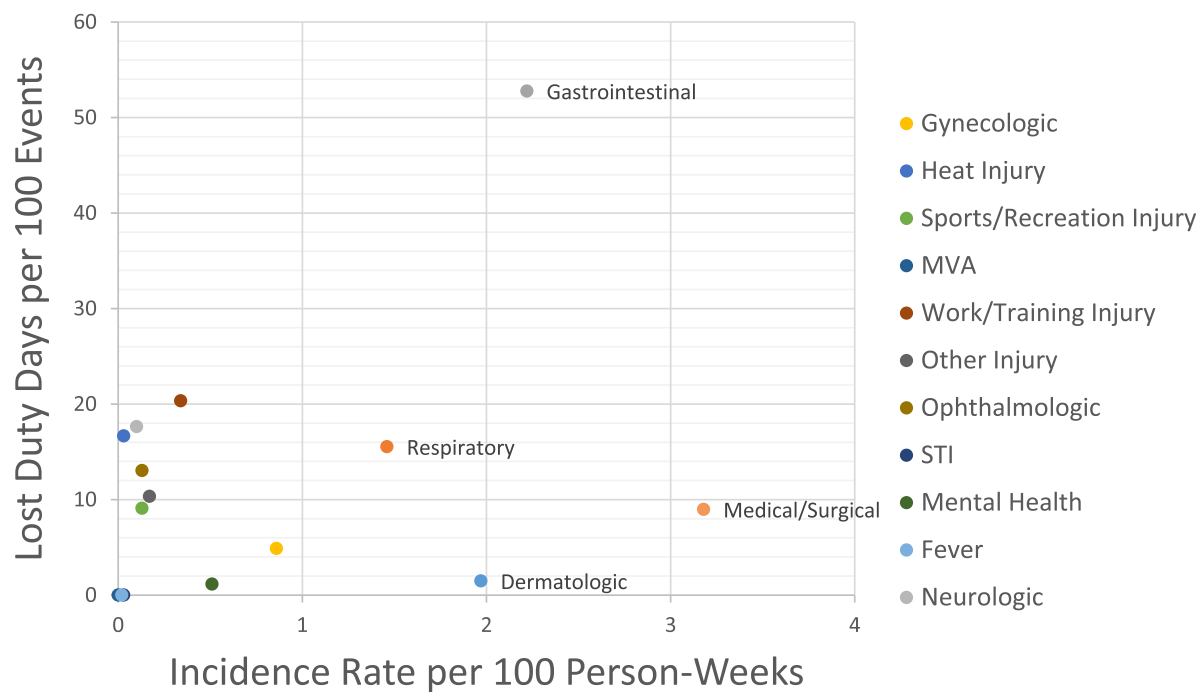

Fig. 1 DNBI Incidence rates and lost work days from clinic data aboard USNS COMFORT during CP11. Events denote corresponding categorical DNBI

Table 3 Personnel reporting DNBI and seeking medical care from questionnaire with differential DNBI counts from CP11

\begin{tabular}{|c|c|c|c|}
\hline & $\begin{array}{l}\text { Reported } \\
\text { DNBI }\end{array}$ & $\begin{array}{l}\text { Reported DNBI and } \\
\text { sought medical care }\end{array}$ & Total \\
\hline $\begin{array}{l}\text { Number of } \\
\text { personnel }\end{array}$ & 921 & 150 & 3156 \\
\hline DNBI & DNBI count & Number seeking care & Percentage (\%) \\
\hline Respiratory & 372 & 59 & 15.9 \\
\hline Dermatologic & 275 & 41 & 14.9 \\
\hline Gastrointestinal & 233 & 54 & 23.2 \\
\hline Gynecologic & 9 & 3 & 33.3 \\
\hline Heat Injury & 59 & 13 & 22.0 \\
\hline $\begin{array}{l}\text { Sports/Recreation } \\
\text { Injury }\end{array}$ & 47 & 12 & 25.5 \\
\hline MVA & 1 & 0 & 0.0 \\
\hline $\begin{array}{l}\text { Work/Training } \\
\text { Injury }\end{array}$ & 31 & 9 & 29.0 \\
\hline Other Injury & 27 & 7 & 25.9 \\
\hline Ophthalmologic & 34 & 9 & 26.5 \\
\hline STI & 1 & 0 & 0.0 \\
\hline Mental Health & 167 & 14 & 8.4 \\
\hline Fever & 48 & 22 & 45.8 \\
\hline Medical/Surgical & 24 & 13 & 54.2 \\
\hline Dental & 3 & 1 & 33.3 \\
\hline Total & 1331 & 257 & 19.3 \\
\hline
\end{tabular}

Personnel may have reported $\geq 1$ DNBI and its impact on DNBI surveillance is needed to better understand this potential phenomenon.

The morbidity measurements in our study indicate underreporting even when the DNBI caused some degree of impact to mission performance. Among those reporting a DNBI on the questionnaire, $36 \%$ reported some degree of impact while only $10 \%$ of these individuals reported seeking medical care. In fact, among the leading categorical DNBI reported as having the most significant impact (i.e., gastrointestinal, respiratory, dermatologic, and mental health), more individuals did not seek care compared to those that did across all impact categories except for respiratory, where those reporting moderate/severe degree of impact were more equally likely to seek care or not seek care. As noted previously, $17 \%$ of individuals reporting a DNBI did not indicate any impact (i.e., no impact, minor impact, moderate/severe impact) with the updated questionnaire, which may have skewed the categorical DNBI identified as having the most severe effects on mission performance. The majority of missing data for DNBI impact came from respiratory, dermatologic and gastrointestinal conditions, which accounts for nearly $70 \%$ of the missing data. However, given that most of the missing data were attributed to those that did not seek medical care, our data still shows that there is significant morbidity from DNBI that is underreported, and perhaps, encouraging self-referral for some of these more common DNBI early may help reduce the impact to overall performance and mission. 
Table 4 Univariate and multivariate analyses of DNBI rates among surveyed personnel aboard USNS COMFORT during CP11

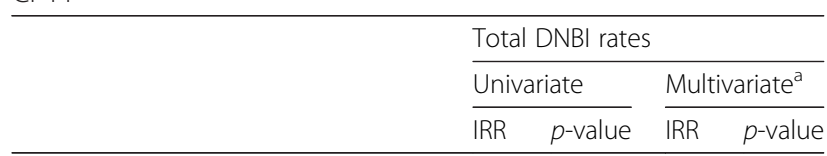

Age

$\leq 25$ (referent)

$1.00 \quad 1.00$

26-35

$36+$

Gender

Male (referent)

Female

1.170 .049

23

$0.87 \quad 0.133$

$0.90 \quad 0.316$

Rank

Enlisted (referent)

Officers

Civilian

Branch of service

Army (referent)
Air Force
Navy
NGO
Other

Days off Ship (continuous)

Location

$\begin{array}{lllll}\text { Jamaica } & 0.75 & 0.036 & 1.07 & 0.672 \\ \text { Peru } & 0.70 & 0.025 & 1.03 & 0.889 \\ \text { Ecuador } & 1.60 & <0.001 & 1.81 & <0.001 \\ \text { Colombia } & 1.39 & 0.001 & 1.39 & 0.002 \\ \text { Nicaragua } & 1.13 & 0.366 & 1.61 & 0.002 \\ \text { Guatemala } & 1.24 & 0.072 & 1.64 & <0.001 \\ \text { El Salvador } & 1.60 & <0.001 & 2.06 & <0.001 \\ \text { Costa Rica } & 0.81 & 0.072 & 1.10 & 0.472 \\ \text { Haiti } & 0.52 & <0.001 & 0.84 & 0.270 \\ \text { Unit department } & & & & \\ \text { Air detachment } & 1.29 & 0.127 & 1.45 & 0.062 \\ \text { Boat detachment } & 0.70 & 0.316 & 0.93 & 0.837 \\ \text { DAS } & 0.82 & 0.166 & 1.05 & 0.795 \\ \text { Destroyer Squadron } & 0.71 & 0.278 & 0.75 & 0.374 \\ \text { DFA } & 0.97 & 0.805 & 1.11 & 0.539 \\ \text { Medical services } & 1.00 & 0.996 & 1.17 & 0.268 \\ \text { Surgical services } & 0.74 & 0.003 & 0.96 & 0.790 \\ \text { Nursing services } & 1.29 & 0.004 & 1.48 & 0.007 \\ \text { Maritime Expeditionary Security } & 0.73 & 0.286 & 1.13 & 0.698 \\ \text { Squadron } & & & & \\ \text { Naval Mobile Construction Battalion } & 2.25 & <0.001 & 3.17 & <0.001 \\ \text { Manpower/Personnel } & 0.83 & 0.453 & 1.20 & 0.521\end{array}$

Table 4 Univariate and multivariate analyses of DNBI rates among surveyed personnel aboard USNS COMFORT during CP11 (Continued)

\begin{tabular}{lllll}
\hline Security & 1.27 & 0.025 & 1.71 & $<0.001$ \\
Information operations & 0.63 & 0.062 & 0.71 & 0.210 \\
Communications & 1.17 & 0.546 & 1.39 & 0.247 \\
Public Affairs Office/Band & 1.29 & 0.174 & 1.35 & 0.164 \\
Translator & 0.90 & 0.665 & 1.01 & 0.969 \\
Operations & 0.93 & 0.799 & 1.16 & 0.589 \\
Other & 0.74 & 0.016 & 0.80 & 0.061 \\
\hline${ }^{a}$ Multivariate analyses adjusted for age, rank and days off ship
\end{tabular}

${ }^{a}$ Multivariate analyses adjusted for age, rank and days off ship

A number of factors were associated with increased rates of DNBI. Compared to the youngest age group $(\leq 25)$, respondents $26-35$ years old had a higher DNBI rate, an effect not observed in the oldest age group (>35). Prior DNBI studies have been mixed showing either no difference or a higher DNBI rate with increasing age $[8,9,16]$. Additionally, prior studies also have shown mixed results for the association between rank and DNBI rates, leading some authors to hypothesize that the increased DNBI rates seen in enlisted personnel may be partly attributed to participation in more hazardous activities [9]. However, we did not observe these findings as our multivariate model showed officers having a higher DNBI rate than the enlisted $(\mathrm{IRR}=1.23, p=0.025)$.

We also found differential risk based on mission location. Ecuador $(I R R=1.81)$ and El Salvador $(I R R=2.06)$ had the highest DNBI rates relative to all other locations. This increased risk of DNBI may be partly attributed to the liberty periods while in Ecuador and to differences in environmental exposures in El Salvador. Particularly for gastrointestinal infections, one of the leading symptomspecific DNBI reported in the questionnaire, the mission locations to Central and South American countries are considered high-risk areas for travelers' diarrhea [18]. Further analyses of food consumption within a host country in relation to symptoms may help discern this potential association. The differential DNBI rates seen among the different countries are unlikely due to the economic status of the host countries given that most mission locations were upper middle and lower middle income countries, and the only low income country, Haiti, did not show any difference in DNBI rates $(p=0.270)$ [15]. Differential rates of DNBI more likely correlated to the exposure of personnel to local foods, which was variable during this deployment. The positive association found between increased rates of DNBI and number of days off the ship (IRR $=1.09, p<0.001$ ) supports this finding. It is also important to take into consideration the incubation time for gastrointestinal and respiratory diseases, which were among the top DNBI. 
Although increased rates were found at specific mission locations, the actual exposure may have been in the prior host country.

Occupation was also associated with differential risk. Service members in nursing services, the construction battalion, and security had the highest risk. A variety of physical and biologic hazards are recognized in nursing related services including ergonomic and lifting injury risks as well as infectious disease exposure, and their close contact with patients often place them at higher risk of occupational exposures compared to other healthcare workers [19]. This may, in part, explain some of the increase in the DNBI rate. The other high risk occupations identified frequently had off-ship exposures and access to non-ship food.

Although our study provides a solid baseline for future hospital ship-based HADR training missions, we also recognize limitations. As with many survey questionnaires that refer to past events, recall bias is a possibility. Furthermore, the questionnaire could have been susceptible to misclassification of categorical DNBI (e.g., sore throat from a respiratory versus a gastrointestinal etiology). We attempted to limit these factors by distributing a weekly survey asking only about events in the preceding week and asking about specific symptoms associated with different categorical DNBI. The survey questionnaire also utilized a convenience sampling method, which is prone to selection bias (healthy worker effect), though the distribution was similar to the overall ship's population based on demographics.

\section{Conclusions}

This study provides the first assessment of DNBI rates and associated impact aboard a US Navy hospital shipbased HADR training mission. We found increased total DNBI rates as well as a low proportion of personnel seeking medical care compared to prior studies. In addition, we found increased DNBI rates associated with several variables (i.e., age, rank, days off ship, unit department). Future studies should confirm and refine these associations. Using DNBI data, investigators should devise strategies for high risk populations and environments that mitigate the detrimental effects of DNBI on mission performance.

\section{Ethics approval and consent to participate}

The data were collected for public health surveillance and monitoring and were not under a research protocol. This analysis and reporting of these data were determined to be exempt from human subjects research by the Uniformed Services University of the Health Sciences Institutional Review Board.

\section{Consent for publication}

This study does not contain any personally identifiable information.

\section{Availability of data materials}

The datasets supporting the conclusions of this article are available through the Naval Medical Research Center in Silver Springs, Maryland, by special request.

\section{Abbreviations}

CP 11: continuing promise 2011; DNBI: disease and non-battle injury; DoD: Department of Defense; Gl: gastrointestinal; HADR: humanitarian aid/ disaster response; IQR: interquartile range; IRR: incidence rate ratio; USNS: United States Naval Ship.

\section{Competing interests}

The authors declare that they have no competing interests.

\section{Authors' contributions}

AC contributed to analysis and interpretation of data as well as drafting the manuscript. AM contributed to acquisition of data and critically revising the manuscript. TB contributed to acquisition of data and critically revising the manuscript. GJM contributed to design and critically revising the manuscript. WTS contributed to conception, design and critically revising the manuscript. CKP contributed to analysis and critically revising the manuscript. MSR contributed to the conception, design, and acquisition of data as well critically revising the manuscript. All authors read and approved the final manuscript.

\section{Acknowledgements}

The authors thank Dr. Cara Olsen for her consultation regarding statistical analyses.

\section{Funding}

This study was not funded. This work was prepared as part of official duties.

\section{Disclaimer}

DoD/USUHS disclaimer: The views expressed are those of the authors and do not necessarily reflect the official policy or position of the Uniformed Services University of the Health Sciences, Department of the Navy,

Department of Defense, or the U.S. Government.

\section{Copyright statement}

All authors are employees of the U.S. Government. This work was prepared as part of official duties. Title 17 U.S.C. \$105 provides that "Copyright protection under this title is not available for any work of the United States Government." Title 17 U.S.C. §101 defines a U.S. Government work as a work prepared by a military service member or employee of the U.S. Government as part of that person's official duties.

\section{Author details}

'Uniformed Services University of the Health Sciences, 4301 Jones Bridge Road, Bethesda, MD 20814, USA. ${ }^{2}$ Enteric Diseases Department, Naval Medical Research Center, 503 Robert Grant Avenue, Silver Springs, MD 20910, USA. ${ }^{3}$ Air Force Global Strike Command, Barksdale Air Force Base, Bossier City, LA, USA. ${ }^{4}$ Department of State, Washington, DC, USA. ${ }^{5}$ Naval Medical Center Portsmouth, Portsmouth, VA, USA.

Received: 26 October 2015 Accepted: 7 April 2016

Published online: 27 April 2016

\section{References}

1. Champion HR, Bellamy RF, Roberts CP, Leppaniemi A. A profile of combat injury. J Trauma. 2003;54:S13-9.

2. Zouris JM, Wade AL, Magno CP. Injury and illness casualty distributions among U.S. Army and Marine Corps personnel during Operation Iraqi Freedom. Mil Med. 2008;173:247-52.

3. Blood CG. Outpatient illness incidence aboard U.S. Navy ships during and after the Vietnam conflict. Mil Med. 1990;155:472-6. 
4. Blood CG, Pugh WM, Gauker ED, Pearsall DM. Comparisons of wartime and peacetime disease and non-battle injury rates aboard ships of the British Royal Navy. Mil Med. 1992;157:641-4.

5. Deputy Secretary of Defense. Joint medical surveillance. Washington: Department of Defense; 1997.

6. Belmont Jr PJ, Goodman GP, Waterman B, DeZee K, Burks R, Owens BD. Disease and nonbattle injuries sustained by a U.S. Army Brigade Combat Team during Operation Iraqi Freedom. Mil Med. 2010;175:469-76.

7. Bohnker BK, Sherman SS, McGinnis JA. Disease and nonbattle injury patterns: afloat data from the U.S. Fifth Fleet (2000-2001). Mil Med. 2003:168:131-4.

8. Riddle MS, Tribble DR, Putnam SD, et al. Past trends and current status of self-reported incidence and impact of disease and nonbattle injury in military operations in Southwest Asia and the Middle East. Am J Public Health. 2008:98:2199-206.

9. Skeehan CD, Tribble DR, Sanders JW, Putnam SD, Armstrong AW, Riddle MS. Nonbattle injury among deployed troops: an epidemiologic study. Mil Med. 2009;174:1256-62.

10. Thompson WT, Cupples ME, Sibbett CH, Skan DI, Bradley T. Challenge of culture, conscience, and contract to general practitioners' care of their own health: qualitative study. BMJ (Clinical research ed). 2001;323:728-31.

11. McKevitt C, Morgan M, Dundas R, Holland WW. Sickness absence and 'working through' illness: a comparison of two professional groups. J Public Health Med. 1997;19:295-300.

12. Davidson SK, Schattner PL. Doctors' health-seeking behaviour: a questionnaire survey. Med J Aust. 2003:179:302-5.

13. Chairman of the Joint Chiefs of Staff. Deployment health surveillance and readiness. Washington: Department of Defense; 1998

14. Navy Environmental Health Center. Implementing guidance for deployment health surveillance. Washington: United States Navy (available at http:// www.public.navy.mil/surfor/Documents/6490_00_1_NMCPHC_TM.pdf) 2000.

15. Chairman of the Joint Chiefs of Staff. Updated procedures for deployment health surveillance and readiness. Washington: Dept of Defense; 2002.

16. Sanders JW, Putnam SD, Frankart C, et al. Impact of illness and non-combat injury during Operations Iraqi Freedom and Enduring Freedom (Afghanistan). Am J Trop Med Hyg. 2005;73:713-9.

17. Riddle MS, Sherman SS, Kilbane EM, Putnam SD. A multivariate analysis of factors associated with differential disease and nonbattle injury and morbidity aboard ships of the U.S. Naval 5th Fleet during peacetime deployment. Mil Med. 2004;169:787-94.

18. Steffen R. Epidemiology of traveler's diarrhea. Clin Infect Dis. 2005;41:S536-40.

19. Stone PW, Clarke SP, Cimiotti J, Correa-de-Araujo R. Nurses' working conditions: implications for infectious disease. Emerg Infect Dis. 2004;10:1984-9.

\section{Submit your next manuscript to BioMed Central and we will help you at every step:}

- We accept pre-submission inquiries

- Our selector tool helps you to find the most relevant journal

- We provide round the clock customer support

- Convenient online submission

- Thorough peer review

- Inclusion in PubMed and all major indexing services

- Maximum visibility for your research

Submit your manuscript at www.biomedcentral.com/submit

C Biomed Central 